\title{
An Inverter Testing System For CRAC
}

\author{
Jiang Wen \\ National Computer network Emergency Response technical \\ Team/Coordination Center, CNCERT/CC \\ Beijing, China
}

\author{
Cao Wenlun, Chen Bei, He Yuyao \\ Northwestern Polytechnical University, NWPU \\ Xi'an, China \\ alawneric@hotmail.com
}

\begin{abstract}
This paper aimed at functional requirements with CRAC (computer room air conditioning) inverter test system, and realized the test system hardware platform design, while completing the software functional design and programming algorithm. For example in Self-Made $10 \mathrm{Kw}$ inverter and Schneider ATV31H $2.2 \mathrm{Kw}$ inverter, we research on its output three-phase voltage, three-phase current for balance analysis and harmonic calculations. Practical application shows that the system can achieve efficient automated test process, and the measurement results with manual measurement are the same.
\end{abstract}

Keywords-Air Conditioner Inverter; variable frequency drives (VFD); Harmonic Analysis; Balance Analysis.

\section{INTRODUCTION}

With the rapid development of communication technology, communications equipment and ancillary equipment energy consumption increases every year. Communication operators and manufacturers pay more and more attention on this issue. It is effectively guarantee the normal operation of communications equipment that extensive use of airconditioning equipment. Meanwhile it brought great energy issues. Data show that: $73 \%$ of the energy consumption of China Mobile is base station energy consume, And the energy consumption rate of $15 \%$ for the communications room. The base station with a room which has $46 \%$ of energy is generated by the air-conditioning, and in the communications room, the air conditioning power consumption accounted for $34 \%{ }^{[1]}$. The computer room precision air-conditioning power consumption accounts for about $50 \%$ of total consumption, the data room is as high as $60 \%{ }^{[2]}$.

Frequency conversion is currently one of the most suitable energy-saving technologies for air-conditioning [3, 4]. This technology aimed to achieve energy-saving by adjustment the conditioning compressor speed, by adjustment of the cooling water pump speed, and by adjustment the speed of the ventilation equipment ${ }^{[5-7]}$. Therefore promotion CRAC frequency conversion energy-saving and performance assessment has great significance for the efficiently operation of the computer room. However there exists no perfect performance test system for inverter. The test systems in article $[8,9]$ do not analyze the inverter output voltage, output current, harmonic and balancing.

The research goal in this paper is the performance of inverter for CRAC and the corresponding testing system; it will

This work was supported in part by the National Natural Science Foundation of China (Grant No. 51377134 \& 6127143).

1. U.S. Government work not protected by U.S. copyright for papers in which all authors are employed by the US government, the copyright notice is:

2. 978-1-4673-6123-1/14/\$31.00 C2014 Crown for papers in which all authors are employed by a Crown government (UK, Canada, and Australia)

3. 978-1-4673-6123-1/14/\$31.00 C 2014 IEEE for all other papers.

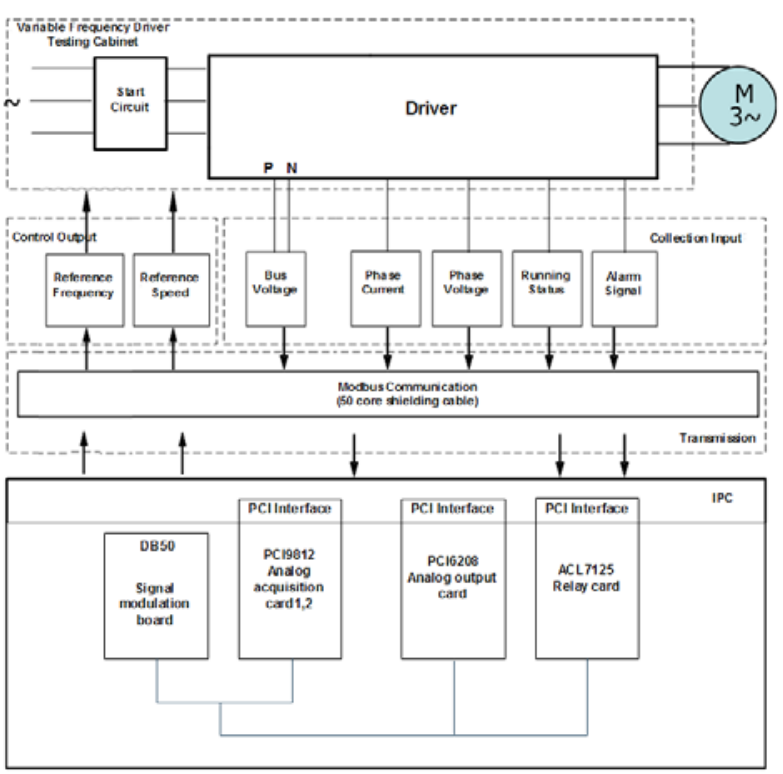

Fig. 1. Structure of System Hardware

be introduced in the second part. The inverter in CRAC than conventional inverter should have a higher frequency stability and harmonic suppression performance, so it is necessary to evaluate the inverter' performance: balancing test method and harmonic test algorithm for inverter testing system will be discussed in Part III. Two Type of motor participate in the experiment. One is the AC asynchronous machine which is used often in traditional CRAC compressor, and the other is $\mathrm{AC}$ permanent magnet synchronous motor which is use for next generation CRAC compressor. The experimental results analysis carried out in the fourth part.

\section{HARDWARE REALIZTION}

The CARC inverter test system hardware structure diagram is showing in Fig.1. It is composed of portable computer and inverter testing cabinet. In the side of portable computer, the portable computer is pluged with PCI9812 acquisition card, ACL7125 relay board, PCI6208 analog output board and SelfMade signal modulation board. Portable computer are used to collecting and analyzing the test signal, meanwhile controling the inverter.

In the side of the testing cabinet, the signal collection board and the inverter to be measured are installed in inverter testing cabinet. LEM LV-25-P voltage sensor, LEM LA-100-P current 
sensor and sampling resistance are set onto the signal collection card. The measurement range of voltage sensor is $0 \sim \pm 14 m A(10 \sim 500 \mathrm{~V})$, and range of the current sensor is $0 \sim \pm 150 \mathrm{~A}$. Then the collection signals which are amplified and isolated will be transmitted to the Self-Made signal modulation board in computer side. The output of the inverter connects on the motor through cables in the cabinet backplane.

The 50 core shielding cable connected on both two sides of computer and the cabinet. All of the collection signals and the control signals joint to Self-Made 50 core duplex cable in backplane of inverter testing cabinet.

The testing system provides eight A/D inputs which are used by three-phase voltage, three-phase current, DC-bus voltage and speed acquisition. The A/D sampling precision is 12 bits, sampling velocity is $20 \mathrm{MHz}$. The analog output card also provides four output channels which are 16 bits analog signals and can output continuous waveform to be used by velocity setting. Meanwhile the analog output card provides four digital input channels and four digital output channels. The digital inputs can be used for servo and overheating alarm signals. The relay card has 12 relay outputs used for enable signal. The Physical Self-Made inverter as well as test systems is shown in Fig.2.
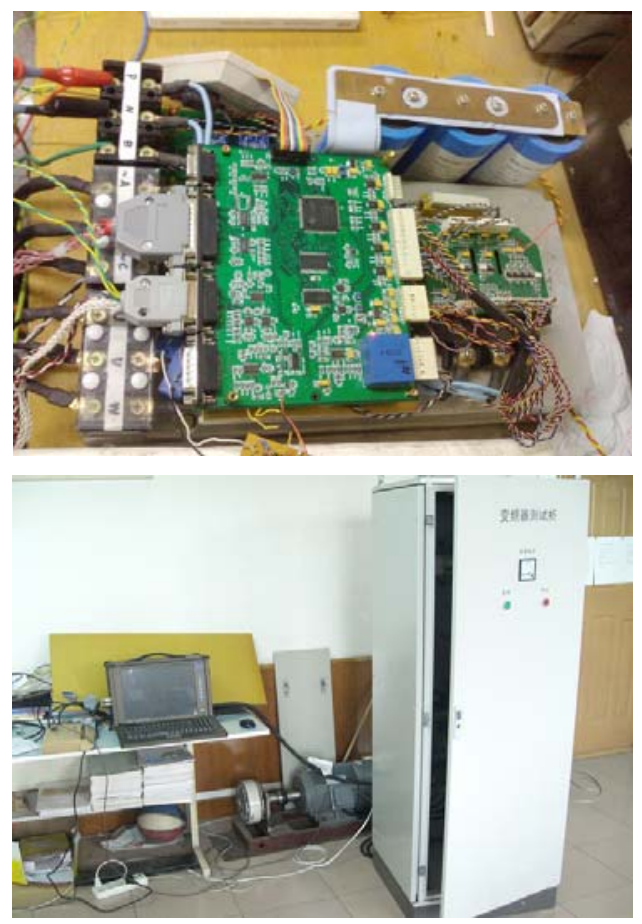

Fig. 2. Physical Self-Made inverter and Test Systems

\section{Testing System Software Design And DATA ANALYSIS ALGORITHM REALIZATION}

\section{A. System Software design}

Air conditioner inverter testing system has the following feather:
- This system can not only automatically measuring the frequency, rotate speed, voltage, current of the inverter output, but also analyzing voltage, current harmonic and balance.

- In the process of testing, the measured data can realize real time numerical and graphic display.

- When the measurement is finished, the analysis reports and characteristic curves of experiments are memorized and output.

- It also supports the inquiry of historical data.

- Performance testing, including sinusoidal tracking test, step response test and etc.

\section{B. Balance Analysis}

The degree of balance of three-phase voltage is as follows.

$$
\varepsilon=\frac{\sqrt{1-\sqrt{3-6 \times L}}}{\sqrt{1+\sqrt{3-6 \times L}}} \times 100 \%
$$

Where $L=\left(a^{4}+b^{4}+c^{4}\right) /\left(a^{2}+b^{2}+c^{2}\right)^{2}$. Here $a, b, c$ is RMS of three-phase voltage.

The balance of three-phase current is similar to the calculation of voltage.

From Fig.3, we can see the inverter has good low speed performance in $10 \mathrm{~Hz}$. And that three-phase current and voltage fastly step into balance state after approximately the 20th sampling point (sampling rates is $1 \mathrm{MHz}$ ).
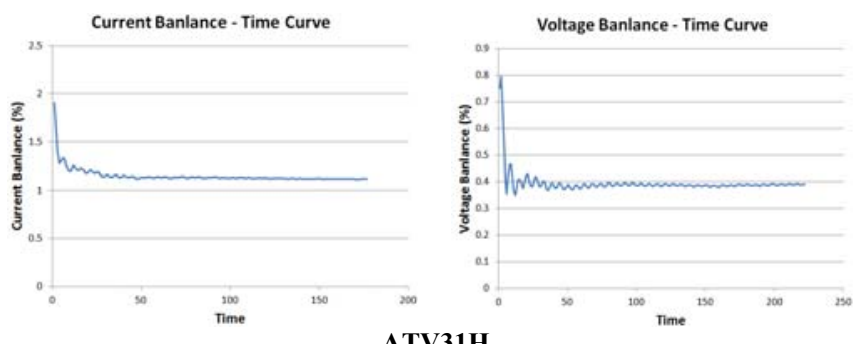

ATV31H

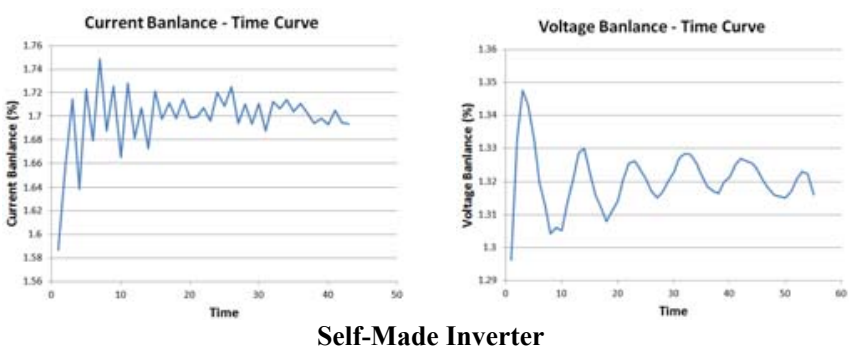

Fig. 3. Balance Analysis with ATV31H and Self-Made Inverter at $10 \mathrm{~Hz}$

\section{Harmonic Analysis \\ 1) Calculation of harmonic}

The harmonic calculation is based on the analysis of current and voltage data of each period. Therefore, it needs to detect whether the collections of collector are in the same period firstly. We use zero-crossing detecting method here. The numerical value of the nth point multiplied by that of the $(n+1)$ th point. If the product is equal or lesser than zero, the 
$(n+1)$ th point is zero-crossing point, marked by $\mathrm{C}(\mathrm{n})$. If this point is set the starting point for the next period, the cutoff of next period is the second zero-crossing point after $n+1$ point, marked by $\mathrm{C}(\mathrm{n}+1)$. The points between $\mathrm{C}(\mathrm{n})$ and $\mathrm{C}(\mathrm{n}+1)$ constitute a cycle.

After the cycle is confirmed, we calculate the voltage, current and harmonic as below ${ }^{[10]}$.

$$
f(t)=A_{0}+\sum_{n=1}^{\infty} A_{n} \cos \left(n \omega t+\varphi_{n}\right)
$$

$A_{0}$ is DC component, $A_{n} \cos \left(n \omega t+\varphi_{n}\right)$ is $n$th harmonic component.

The equation above can be deformed as follows.

$$
f(t)=a_{0}+\sum_{n=1}^{\infty}\left(a_{n} \cos n \omega t+b_{n} \sin n \omega t\right)
$$

where

$$
\begin{aligned}
& A_{0}=a_{0} \\
& a_{n}=A_{n} \cos \varphi_{n} \\
& b_{n}=-A_{n} \sin \varphi_{n} \\
& \varphi_{n}=-\arctan \frac{b_{n}}{a_{n}}
\end{aligned}
$$

Here

$$
\begin{aligned}
& a_{0}=\frac{1}{2 \pi} \int_{-\pi}^{\pi} f(t) d t \\
& a_{n}=\frac{1}{2 \pi} \int_{-\pi}^{\pi} f(t) \cos n \omega t d t \\
& b_{n}=\frac{1}{2 \pi} \int_{-\pi}^{\pi} f(t) \sin n \omega t d t
\end{aligned}
$$

From formula (3) we can calculate the measured current and the nth harmonic component of voltage.

\section{2) Calculation of harmonic ratio and harmonic distortion}

We use the root mean square value (RMS) of voltage and current to compute the harmonic ratio and harmonic distortion. By the following formula, the voltage harmonic can be gained.

The $h$-th harmonic voltage ratio is $H R U_{k}$.

$$
H R U_{h}=\frac{U_{h}}{U_{1}} \times 100 \%
$$

Here $U_{h}$ hth harmonic voltage (root mean square value), $U_{1}$ is fundamental voltage (RMS).

Harmonic voltage ratio $U_{H}$ is

$$
U_{H}=\sqrt{\sum_{h=2}^{\infty}\left(U_{h}\right)^{2}}
$$

Total voltage harmonic distortion $T H D_{u}$ is

$$
T H D_{u}=\frac{U_{H}}{U_{1}} \times 100 \%
$$

The calculation of current harmonic is as same as that of the voltage.

\section{RESUlt ANALYSIS}

In the hardware platform of above testing system, we use hybrid programming technique of $\mathrm{VC}++6.0$ and $\mathrm{NI}$ control to implement the testing system software. The inverter testing system software human-machine interface and the example style of report form are shown in Fig.4.

On condition that the Schneider ATV31H $2.2 \mathrm{Kw}$ inverter control $2.2 \mathrm{Kw}$ asynchronous AC motor-SIMO YJ TG132S-8A with no load, the full range calculations of voltage harmonic, current harmonic and balance are fulfilled. The part of testing results is shown in Fig.3, TABLE I and TABLE II. The
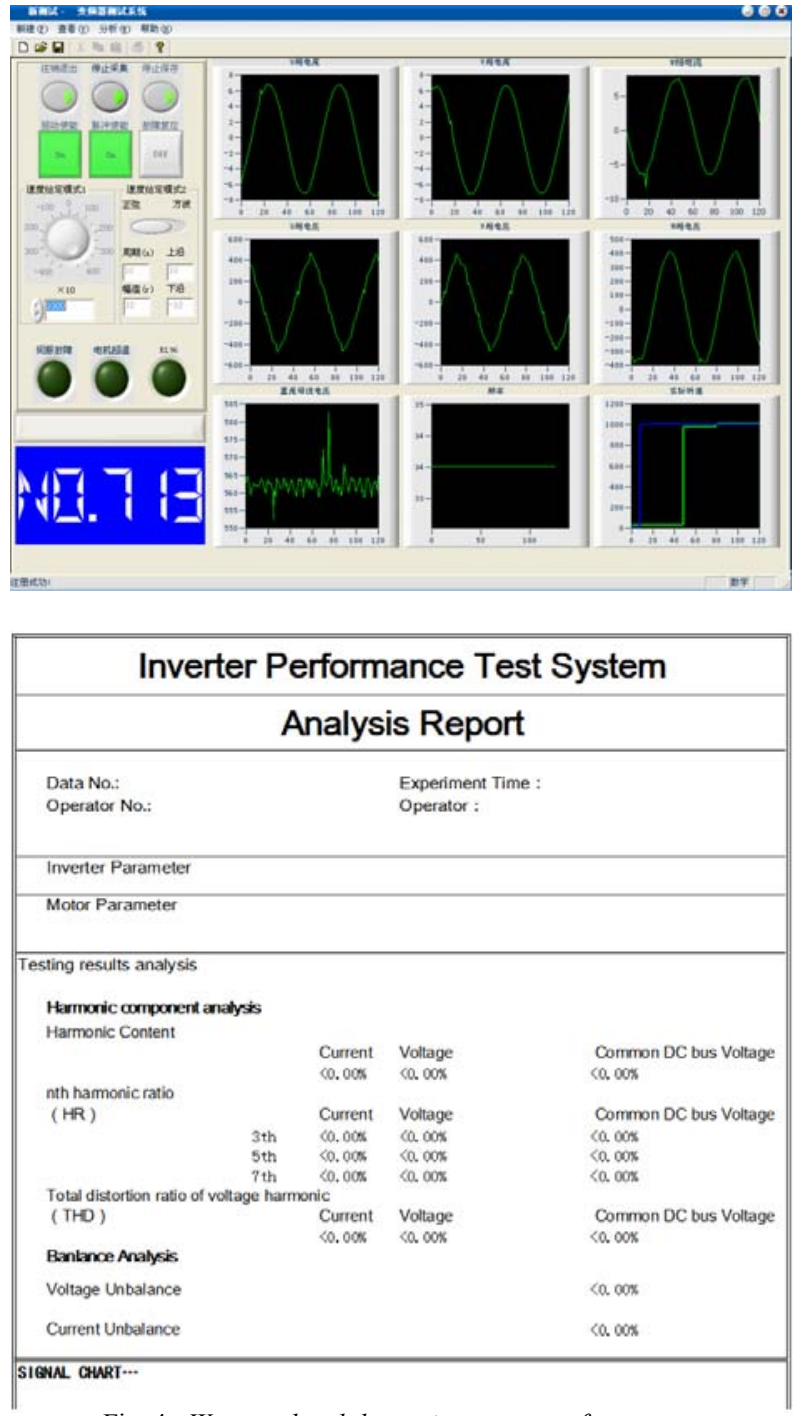

Fig. 4. We completed the testing system software too.

Testing system software interface and the style of report forms are showing here. 
parallelism test results on Self-Made $10 \mathrm{Kw}$ inverter with 9.5Kw PMSM-SIEMENS 1FT6-084-8SH71-3AE3 (no load) are contrasting with ATV31H in the corresponding position.

In Fig.3, when the system runs at $10 \mathrm{~Hz}$, it shows that the balance of voltage and current at start-up stage are worse than the balance at stable operation. With the increasing of time, the system balance gradually tends to a constant (which is consistent with the manual measurement). A large number of tests show that within the range of speed regulation, the balance calculations on different frequencies have the analogous results with Fig.3. Self-Made inverter has the similar performance in output balancing with ATV31H.

From TABLE I and TABLE II, it shows that the 3th to 7th harmonic of this inverter are more worthy of attention than the higher times harmonic within the range of speed regulation. The total harmonic distortion ratio of current is within $2 \%$ and that value of the voltage is within $7 \%$ for ATV $31 \mathrm{H}$, which is also consistent with the actual situation. As can be seen from the comparison in TABLE I and II, Self-Made inverter have better harmonic suppression performance. The total harmonic distortion ratio of current is nearly $1 \%$, meanwhile the total harmonic distortion ratio of voltage is within $3 \%$.

\section{CONCLUSIONS}

The system hardware and software implemented the collection and storage of real time data of CRAC inverter

TABLE I. HARMONICS OF A-PHASE VOLTAGE ON DIFFERENT FREQUENCIES

\begin{tabular}{|c|c|c|c|c|c|c|c|c|c|c|}
\hline & Frequency & 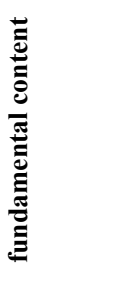 & 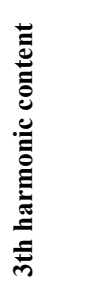 & 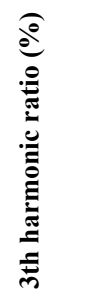 & 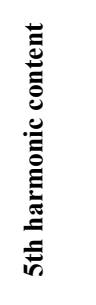 & 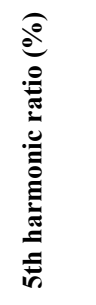 & 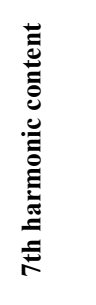 & 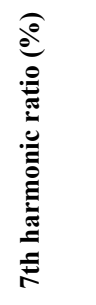 & 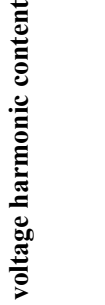 & 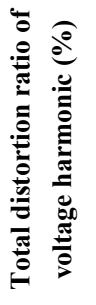 \\
\hline \multirow{6}{*}{$\begin{array}{c}\text { SCHNEIDE } \\
\text { R ATV31H } \\
\text { INVERTER }\end{array}$} & $2 \mathrm{~Hz}$ & 28.1000 & 0.6900 & 2.4555 & 0.2940 & 1.0463 & 0.2050 & 0.7295 & 0.7775 & 2.7670 \\
\hline & $10 \mathrm{~Hz}$ & 125.0000 & 0.3350 & 0.2680 & 0.5330 & 0.4264 & 1.0400 & 0.8320 & 1.2157 & 0.9726 \\
\hline & $20 \mathrm{~Hz}$ & 240.0000 & 2.3900 & 0.9958 & 0.8600 & 0.3583 & 0.1630 & 0.0679 & 2.5452 & 1.0605 \\
\hline & $30 \mathrm{~Hz}$ & 324.0000 & 20.9000 & 6.4506 & 0.5920 & 0.1827 & 0.6300 & 0.1944 & 20.9179 & 6.4561 \\
\hline & $40 \mathrm{~Hz}$ & 422.0000 & 7.4100 & 1.7559 & 0.7900 & 0.1872 & 0.2663 & 0.0631 & 7.4567 & 1.7670 \\
\hline & $50 \mathrm{~Hz}$ & 480.0000 & 2.1500 & 0.4479 & 0.7060 & 0.1471 & 1.4900 & 0.3104 & 2.7094 & 0.5645 \\
\hline \multirow{6}{*}{$\begin{array}{c}\text { SELF-MADE } \\
\text { 10KW } \\
\text { INVERTER }\end{array}$} & $2 \mathrm{~Hz}$ & 25.0000 & 0.5021 & 2.0084 & 0.4541 & 1.8164 & 0.1223 & 0.4892 & 0.6879 & 2.7517 \\
\hline & $10 \mathrm{~Hz}$ & 110.0000 & 0.6170 & 0.5609 & 0.3015 & 0.2740 & 0.1201 & 0.1091 & 0.6971 & 0.6337 \\
\hline & $20 \mathrm{~Hz}$ & 210.0000 & 2.0314 & 0.9673 & 0.5251 & 0.2500 & 0.3125 & 0.1488 & 2.1213 & 1.0101 \\
\hline & $30 \mathrm{~Hz}$ & 302.0000 & 5.2146 & 1.7266 & 1.2568 & 0.4161 & 0.2510 & 0.0831 & 5.3697 & 1.7780 \\
\hline & $40 \mathrm{~Hz}$ & 390.0000 & 4.2145 & 1.0806 & 0.6849 & 0.1756 & 0.0457 & 0.0117 & 4.2700 & 1.0940 \\
\hline & $50 \mathrm{~Hz}$ & 480.0000 & 2.1549 & 0.4489 & 1.0256 & 0.2136 & 0.6987 & 0.1455 & 2.4866 & 0.5180 \\
\hline
\end{tabular}

TABLE II. HARMONICS OF A-PHASE CURRENT ON DIFFERENT FREQUENCIES

\begin{tabular}{|c|c|c|c|c|c|c|c|c|c|c|}
\hline & Frequency & 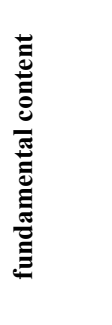 & 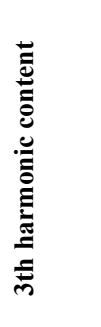 & 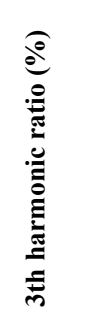 & 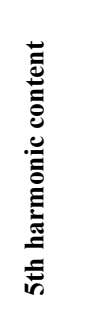 & ễ & 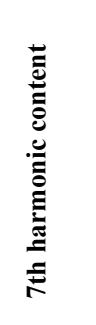 & 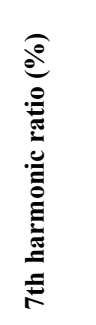 & 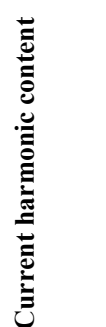 & 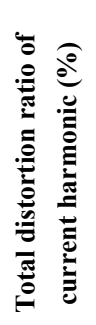 \\
\hline \multirow{6}{*}{$\begin{array}{c}\text { SCHNEIDE } \\
\text { R ATV31H } \\
\text { INVERTER }\end{array}$} & $2 \mathrm{~Hz}$ & 4.3200 & 0.0744 & 1.7222 & 0.0416 & 0.9630 & 0.0092 & 0.2125 & 0.0857 & 1.9846 \\
\hline & $10 \mathrm{~Hz}$ & 6.6800 & 0.0269 & 0.4027 & 0.0581 & 0.8698 & 0.0526 & 0.7874 & 0.0829 & 1.2404 \\
\hline & $20 \mathrm{~Hz}$ & 4.6500 & 0.0348 & 0.7484 & 0.0083 & 0.1785 & 0.0119 & 0.2559 & 0.0377 & 0.8108 \\
\hline & $30 \mathrm{~Hz}$ & 6.6000 & 0.0281 & 0.4258 & 0.0049 & 0.0736 & 0.0042 & 0.0638 & 0.0288 & 0.4368 \\
\hline & $40 \mathrm{~Hz}$ & 6.5700 & 0.0243 & 0.3699 & 0.0120 & 0.1826 & 0.0030 & 0.0461 & 0.0273 & 0.4151 \\
\hline & $50 \mathrm{~Hz}$ & 5.5400 & 0.0188 & 0.3394 & 0.0257 & 0.4639 & 0.0154 & 0.2780 & 0.0354 & 0.6385 \\
\hline \multirow{6}{*}{$\begin{array}{c}\text { SELF-MADE } \\
\text { 10KW } \\
\text { INVERTER }\end{array}$} & $2 \mathrm{~Hz}$ & 5.0200 & 0.0424 & 0.8446 & 0.0254 & 0.5059 & 0.0145 & 0.2888 & 0.0515 & 1.0260 \\
\hline & $10 \mathrm{~Hz}$ & 5.0000 & 0.0315 & 0.63 & 0.0115 & 0.23 & 0.0014 & 0.028 & 0.0335 & 0.6712 \\
\hline & $20 \mathrm{~Hz}$ & 5.1100 & 0.0359 & 0.7025 & 0.0154 & 0.3013 & 0.0022 & 0.0430 & 0.0391 & 0.7656 \\
\hline & $30 \mathrm{~Hz}$ & 4.9300 & 0.0321 & 0.6511 & 0.0164 & 0.3326 & 0.0047 & 0.0953 & 0.0363 & 0.7373 \\
\hline & $40 \mathrm{~Hz}$ & 4.8800 & 0.0219 & 0.4487 & 0.0047 & 0.0963 & 0.0142 & 0.2909 & 0.0265 & 0.5434 \\
\hline & $50 \mathrm{~Hz}$ & 5.0000 & 0.0203 & 0.406 & 0.0021 & 0.042 & 0.0002 & 0.004 & 0.0204 & 0.4081 \\
\hline
\end{tabular}


testing system. The data are well verified by Fluke Power Quality Analyzerl. Meantime the curves of three-phase voltage and current, DC bus voltage, frequency, rotate speed are drawn. We also output report and analyze the balances of three-phase voltage and current, harmonic content. Additionally, we integrated some customised function such as: servo ready, error state report(motor overheat, servo error etc), and some typical running control(sine evaluation, sudden stop, etc). The actual use of that system is running well automatically.

\section{REFERENCES}

[1] Available: http://acc.chinaiol.com/j/0820/2239479.html.

[2] Ding Qiang; Han Meng. (2009). "Computer room energy saving in communication bureau station". Communication and Technical Standards. Available: http://www.ptsn.net.cn/article_new/dload_article.php?article_id=technic

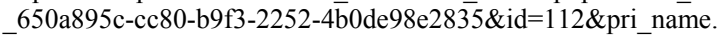

[3] Sae-Kok W, Yokoyama A, Ogawa S, Verma S C(2002). "Nonlinear excitation control for rotary type frequency converter using two sets of adjustable speed generators/motors". Transmission and Distribution Conference and Exhibition, Vol.1, pp.195-200.
[4] Economization, A., Indirect, U., \& Cooling, E. NSIDC Data Center: Energy Reduction Strategies.

[5] Available:http://www1.eere.energy.gov/femp/pdfs/nsidc_dcstrategies.pd

[6] Sundaralingam, V.; Kumar, P.; Joshi, Y. (2011). "Server heat load based CRAC fan controller paired with rear door heat exchanger," In ASME 2011 Pacific Rim Technical Conference and Exhibition on Packaging and Integration of Electronic and Photonic Systems, Vol. 2, pp.489-496.

[7] Bash, C. B.; Patel, C. D.; Sharma, R. K. (2006, May). "Dynamic thermal management of air cooled data centers," In Tenth Intersociety Conference on Thermal and Thermomechanical Phenomena in Electronics Systems. Available: http://ieeexplore.ieee.org/xpls/abs_all.jsp?arnumber $=1645377$

[8] Ma, Z.; Wang, S. (2009). "Energy efficient control of variable speed pumps in complex building central air-conditioning systems". Energy and Buildings, Vol.41(2), pp.197-205.

[9] Chen Xiaoping; Li Yunfei. (2004) "Development of Inverter Testing System Based on Virtual Instrument Technology". Chinese Journal Of Scientific Instrument, Vol.25(5), pp.684-687.

[10] Qiang Zhang; Peiyuan Cheng; et al. (2009). "Software Design of Testing System for Frequency Converter Generator Sets Based on Virtual Instrument", ICEMI, Vol.1, pp.11009-11013.

[11] Wu Zhongzhi; Wu Jialin. Inverter principle and application guide. Beijing: China Electric Power Press, 2007. 